\title{
ALTERNATIVAS DE FINANCIACIÓN DE LAS PYME: POSIBILIDAD DE DESARROLLO
}

\author{
CPC. Eduardo A. Montes Farro* \\ Mg. Jeri Ramón Ruffner** \\ Dr. Luis Bortesi Longui*** \\ Abog. Lourdes Calderón Aguilar ${ }^{* * * *}$ \\ CPC Vladimir Rodríguez Cairo*****
}

La Tierra tiene lo suficiente para las necesidades de todos; pero no para las

ambiciones de unos pocos

Mahatma Gandhi

\section{Introducción}

El tema de las PYME es de mucha actualidad, no sólo a nivel nacional si no en todo el mundo, donde ha contribuido a mantener un desarrollo económico sostenido.

En el Perü hay mucha expectativa, pero todavia no iniciamos el despegue económico. De allí surgió nuestro interës sobre el tema.

\section{Significado de PYME}

- En el Perí: Pequeña y Microempresa

- En el resto del mundo: Pequeñay Mediana Empresa

Estas Pyme representan el sector más importante y dinámico de la economia de los paises.
Por la importancia del número de las Microempresas, más no por el volumen de la producción, se quiere articular este conjunto de empresas para que pueda solucionar, en parte, el problema del desempleo.

No se piense que el desarrollo de las Pyme es la solución de desarrollo (en el nuevo proyecto de Ley las llama, para distinguir, MYPE, Micro y Pequeñas Empresas.

Al irnos aproximando al tema de las Pyme, con la intención de poder recomendar instrumentos propios de nuestra profesión, que ayuden a las Pyme, a desarrollarse económica y financieramente; nos encontramos que se trata de un problema social, económico y político muy amplio.

Para ilustrar la situación, tal vez exagerando un poco, podemos mencionar lo siguiente:

- Profesor Asociado de la Facultad de Ciencias Contables

- Profesora Asociada de la Facultad de Ciencias Contables

- Profesor Auxiliar de la Facultad de Ciencias Contables

* Profesora Auxiliar de la Facultad de Ciencias Contables

Profesor Contratado de la Facultad de Ciencias Contables 
Actualmente, en el congreso se ha planteado que las Universidades Estatales sigan siendo gratuitas, pero que los alumnos deben pagar. Esto denota por lo menos ineptitud. Si se sigue asi, la población tendrá que crear miniescuelas, minicolegios y Microuniversidades; todo el que sepa leer, podria fundar en su casa un centro educativo; y como mal que bien funcionaria, se pensará que hay que promover las PYMEDUCAS. La verdad, ya no sabemos si estamos exagerando.

Consideramos necesario repasar algunos conceptos y cifras.

\section{Finanzas Públicas}

Ante el incremento del déficit fiscal se tiene que cubrir mediante:

a) Emisión de Bonos Públicos. Esto se ha hecho, generando más deuda.

b) Incremento de la Recaudación. Aquí tenemos los esfuerzos de la Sunat y la Sunad, existe mucho por recaudar. Tanto por el tema de las exoneraciones como el Contrabando, que parece que quieren poner a los ratones de despenseros. c) Recorte de la Inversión. El país lo que necesita es inversión, asi que no es conveniente reducir por este lado

d) Recorte del Gasto. En un presupuesto pequeño es difícil reducir gastos, pero es notorio que se puede reclasificar el gasto, en aspectos que todos conocemos y sufrimos.

\section{Balanza Comercial Deficitaria}

Es ilustrativa la comparación de las cifras de Exportación Per Cápita del Perú con otros países latinoamericanos:

$\begin{array}{ll}\text { PERÜ } & \text { US\$260 } \\ \text { MÉXICO } & \text { US\$1.500 } \\ \text { CHILE } & \text { US\$1.300 }\end{array}$

Esta es una realidad que hay que revertir

\section{Situación Económica del País}

Del PBI de US\$ 60,000', el $80 \%$ corresponde al consumo; y sólo el $20 \%$ a la Inversión.

Somos un pais de consumidores

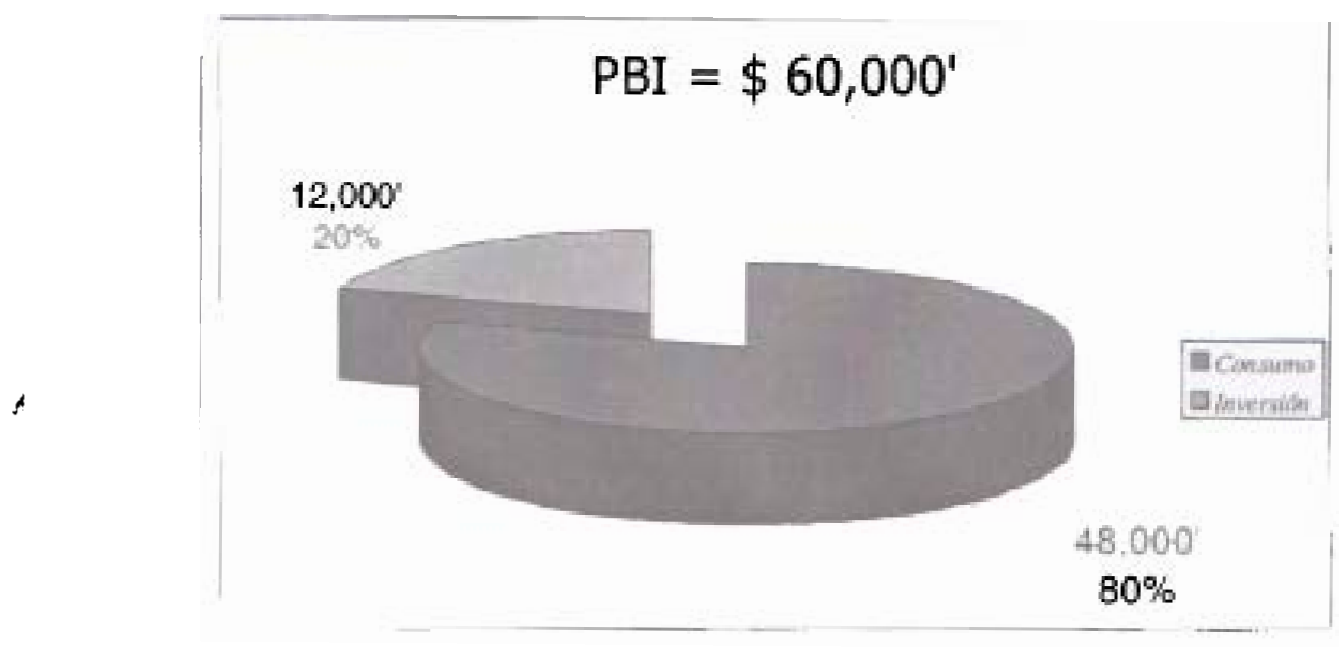


El acuerdo del ATPA (ley de Preferencias Comerciales Andinas), podría ser fundamental para lograr el incremento de los ingresos y equilibrar nuestra balanza comercial.

El sector más beneficiado debería ser el conformado por las PYME.

Se debe orientar mucho esfuerzo para fortalecer las microempresas, para que dejen de serlo. Creemos que está claro. Las Microempresas no deben ser el eje de la economía.

\section{Desempleo y Pobreza}

- El desempleo alcanzó el $10 \%$

- La pobreza extrema subió al 24.45 en el año 2001.

- En los departamentos de Huancavelica, Huanuco, Apurímac y Puno, predomina la pobreza extrema.

Las cifras obligan a tener una muy seria reflexión de parte de todos.

En el Registro Empresarial por sectores, encontramos que:

Grandes y Medianas Empresas 3,019

Pequeñas y Microempresas $\quad 813,072$

Dentro del universo de las PYME, el $80.8 \%$ se dedica al Comercio y el $10.8 \%$ a la Industria.

Aspectos Esenciales de la Pequena y Microempresa. Se denomina Pequeña y Microempresa a la unidad económica operada por una persona natural o juridica, con la finalidad de desarrollar actividades de comercialización de bienes, prestaciôn de servicios, etc.

\section{Caracteristicas Generales}

- Micro empresa. El número total de trabajadores no excede de diez personas.

- Pequeña empresa. El número total de trabajadores es mayor de diez, pero no excede de cuarenta personas.

Parámetros tentativos que sólo considera el número de trabajadores.

La caracterización de las PYME por el número de trabajadores es incorrecta. La preocupación por atender la desocupación desvirtúa el tema de producción; además que no es cierto que cuanto más trabajadores tiene la empresa es mảs importante.

\section{FORMALIZACIÓN DE LAS PYME}

Régimen Tributario. Las PYME, de acuerdo a su naturaleza, están sujetas al régimen tributario correspondiente establecido en la normatividad vigente, por lo tanto no gozan de ningún régimen especial.

Es bueno que las PYME sean consideradas de acuerdo al tipo de actividad, sin mayores distingos.

Pero existe un escenario que desfavorece el desarrollo de las PYME. El Régimen Único Simplificado (RUS), en el que se encuentran muchas PYME, comprende el Impuesto a la Renta y el I.G.V. para las actividades generadoras de rentas de Tercera Categoría. Estas entidades emiten Boletas de Venta, que no permiten a las empresas adquirientes ejercer el derecho de Crédito Fiscal, ni podrán sustentar gastos o costos para efecto tributario, salvo un porcentaje mínimo y hasta un límite máximo. Las posibilidades de la demanda por bienes 
y servicios de las Microempresas disminuyen; $y$ se reduce las posibilidades de desarrollo.

\section{Situación de las Pyme}

Debemos repetir que el término PYME se utiliza en otros países como Pequeña y Mediana empresa; en el Perú se considera a las microempresas, por su importancia numérica. Aunque actualmente se piensa modificar el término.

Para que la gestión financiera permita saldos de caja positivos, utilidades y rentabilidad; y posibilite el crecimiento empresarial, es necesario contar con accesibilidad al crédito.

En la actualidad las principales instituciones financieras difícilmente otorgan créditos a este sector; y si lo hace ponen condiciones excesivas.

Podemos afirmar que el entorno financiero no constituye un instrumento de desarrollo de las empresas en general, si no todo lo contrario.

Como ejemplo podemos ver las

de interés, de cualquier dia:

\begin{tabular}{|l|l|l|l|l|} 
& & USA USS & & \\
\hline $\begin{array}{l}\text { Comercial } \\
\text { Microempresa }\end{array}$ & & $\begin{array}{l}\text { Ahorros } \\
\text { Plazo }\end{array}$ & \\
Consumo & & CTS & & \\
Hipotecario & & & & \\
Tasa Libor & & & & \\
\hline
\end{tabular}

La enorme diferencia de las Tasas Activas y Pasivas en los Bancos, define el costo de financiación del Capital de Trabajo de las empresas; y desalienta el Ahorro.

La Libor (London Interbank Offered Rate) Tasa de Interés Interbancaria ofrecida en Londres, nos da un buen referente.

\section{Dificultades y Debilidades}

- Entre los obstáculos para acceder al financiamiento de las PYME desde el punto de vista de la demanda se encuentran el alto costo del crëdito, la falta de confianza de las entidades financieras respecto de los proyectos, el exceso de burocracia de los intermediarios financieros; y la petición de excesivas garantías y plazos muy cortos

- Desconocimiento de técnicas de gestión

- Falta de información del mercado, interno y externo

- No se superan las dificultades, fundamentalmente por falta de información y creatividad.

Licencia de Funcionamiento.- Para efectos de la licencia Municipal de 
Funcionamiento Provisional o Definitiva, califican como PYMES aquellas que cumplan las caracteristicas siguientes:

\section{Microempresa}

- El numero total de trabajadores no excede de diez personas

- El valor total anual de las ventas no excede de cien unidades impositivas tributarias.

\section{Pequeña Empresa}

- El valor total anual de las ventas no excede de Doscientas (200) Unidades Impositivas Tributarias.

- El número total de trabajadores no excede de cuarenta (40) personas.

Dichas características podrán ser actualizadas o modificadas total o parcialmente mediante Decreto Supremo refrendado por el Ministro de Industria, Turismo, Integración y Negociaciones Comerciales Internacionales.

\section{Necesidades de Inversión}

\section{De Capitales}

De Tecnologia

Mucho se repite la necesidad de Inversión Extranjera, porque en el país no tenemos Capitales, ni Tecnología. Siendo verdad, no es toda la verdad.

Podemos tomar como ejemplo 3 paises:

EEUU, Alemania y Japón; para no mencionar las Koreas y China (segunda potencia económica del mundo).

EEUU es relativamente una nación joven de inmigrantes. Alemania, ha resurgido de una catástrofe bélica.
Japón, igualmente rendido ante la bomba atómica, e intervenido después de la derrota.

Todos se han desarrollado por medio de la inversión inteligente de sus recursos. No sólo de Capitales Monetarios, que en buena cuenta sólo representan derechos por el esfuerzo organizado y persistente de sus dirigentes y población en general.

\section{Fuentes de Financiamiento}

Se cuenta con una serie de posibilidades: desde el crédito de los proveedores; el Leasing, convenio contractual que permite acceder a Activos $e$ ir pagando a mediano o largo plazo; y los habituales modos de financiamiento del Sistema Financiero.

La dificultad de las PYME, para presentar garantías acostumbradas, que respalden la operación de crédito, limita su capacidad para obtener préstamos porque el valor de los Activos o el monto del Capital Societario, no cubre los requisitos con relación al crédito solicitado.

Es necesario poder cuantificar la gran potencialidad de las PYME, basada en el empeño persistente y esforzado de las personas que las constituyen.

\section{Problemática}

Revisando la situación, encontramos:

Crédito escaso, de alto costo y plazos muy cortos

Desconocimiento de técnicas de gestión: Tecnologías de Organización, 
Producción, Comercialización y Financiamiento adecuado a la realidad nacional.

Falta de información del mercado, interno y externo

- Al plantear las dificultades de las pequeñas y microempresas, encontramos una gran debilidad estructural de la economía del país.

Las empresas más importantes, no tienen la solidez y capacidad de cubrir la demanda nacional; y menos competir en el Mercado Externo, salvo en ciertos aspectos y condiciones favorables o de equidad.

\section{Organismos de Apoyo}

- Prompyme

- Prompex

- Parques industriales

- Maquicentros

- Edipymes

- Comide

Se ha venido creando una serie de instituciones para apoyar y promover el desarrollo de las Pyme, pero todavía no se logra articular eficientemente los recursos y esfuerzos.

Podemos señalar como ejemplo la Feria Internacional PERUSA EXPO 2002 en Miami, donde hubo un gran desconcierto en los expositores peruanos, por falta de asesoría de Prompex. Pero, si los esfuerzos y errores son inteligentemente utilizados se podrá obtener buenos resultados en el futuro.
Para incentivar la comercialización tenemos a Prompyme. Prompex para la exportación. Para fomentar la capacitación, intercambio de experiencias y difusión, los Parques Industriales y Maquicentros.

Para la Financiación: Fondos de Garantía y Seguros de Crédito, las Cajas Municipales, Cajas Rurales y las Edypymes, empresas de desarrollo crediticio.

Cofide negocia líneas de financiamiento a través de las empresas del sistema financiero.

También está mejorando las Compras estatales, y el fomento de Consorcios y Ferias.

\section{Conclusiones}

- Elevado costo financiero

- Deficiente información de Organización, Producción, Comercialización y Financiación

- La Informalidad: La falta de profesionalización en todos los niveles y sectores, crea desconcierto y encarecimiento

Estamos viviendo un momento histórico muy interesante: Hemos tenido una serie de experiencias negativas que nos han obligado $y$ están obligando a pensar qué cosas hacer y cómo hacerlas.

Desde bastante tiempo nos acondicionan de una $u$ otra forma a no pensar, sino aceptar nuevos dogmas y costumbres que no son saludables para nosotros.

Consideramos que este es el gran paso: Pensar. 
Traerá como consecuencia Creer en nosotros; y, después, determinar en que consiste nuestro bienestar y cómo conseguirlo. Esto también es invertir.

\section{Recomendaciones}

Se debe propiciar:

- El desarrollo exportador de las Pyme a través de Consorcios de Exportación

- La creación de un ambiente de confianza y garantía en las Instituciones Crediticias para que flexibilicen sus exigencias para conceder los fondos necesarios.

- El conocimiento para diseñar Proyectos de Inversión rentables

- La capacitación en las técnicas de gestión empresarial.

- Aglutinando por tipo de productores, se haría posible grandes y regulares volúmenes de exportación

- Crear un Fondo de Garantía, constituido en parte por los aportes periódicos de las Pyme. Las entidades crediticias podrían calificar como buenos posibles clientes a quienes cumplieran con dichos aportes.

- Debemos recordar que en las decisiones financieras lo primero que se debe sustentar es el Proyecto de Inversión, es decir en qué vamos a usar los fondos, y si es factible su rentabilidad; lo segundo determinar de donde conseguir el dinero.

- El conocimiento de las herramientas que permitan la eficiencia de la empresa.
Como vemos corresponde a nociones para todo tipo de empresas; sólo que las pequeñas $y$ microempresas necesitan apoyo, como los niños requieren de nuestra ayuda para que se desarrollen.

\section{Colofón}

- 813,000 empresas

Aquí se puede hacer la siguiente reflexión: Si el sector de las Pequeñas y Microempresas tienen notables carencias de tipo profesional y financieras.

¿De qué forma podemos, los Profesionales, contribuir al Desarrollo Empresarial?

813,000 empresas nos esperan. Los profesionales, poseen conocimiento de Costos de la Producción y Comercialización, Formulación y Evaluación de Proyectos de Inversión, de obligaciones Tributarias, determinar las necesidades de Fondos y cuales son las más convenientes Fuentes de financiación; también Comercio Internacional y la Negociación con las Entidades Financieras. ¿Tenemos que esperar que cada empresita solicite nuestros servicios individualmente? Creemos que tenemos un reto muy interesante para ofrecer propuestas de solución a la demanda profesional, particularmente urgente de este segmento de la economia.

\section{BIBLIOGRAFÍA}

1. Guía para la Constitución de una entidad de desarrollo para 
las Pequeñas y Microempresas EDPYMES - SBS - 1995

2. Comentarios de la Resolución SBS No. 897-94-Cofide

3. Acceso de las Pequeñas y Medianas empresas al financiamiento-Grupo DFC Washington - Marzo 2002

4. Proyecto de Ley MYPE - 2002

5. PYMES, su economia y organización-Horacio Irigoyen - 1997

6. La Estructura empresarial en el Perú-Fernando Villarán
7. Datos Estadísticos - INEI

8. La Microempresa y los Bancos Maria Cavero Barra - agosto 2002

9. Informe sobre los requerimientos de las PYMES para impulsar el Comercio Interregional - ALADI

10. Tecnologías de la Información aplicadas a las Micro y Pequeñas Empresas - http://www.sipromicro. org/foro/list.php?f $=4$

11. Mayor productividad y un mejor lugar de trabajo - OIT - Lima 